\title{
Efeitos do conflito armado sobre a vida e a saúde na Colômbia
}

\author{
The effects of the armed conflict on the life and health in Colombia
}

Saúl Franco ${ }^{1}$

Clara Mercedes Suarez ${ }^{1}$

Claudia Beatriz Naranjo ${ }^{1}$

Liliana Carolina Báez ${ }^{1}$

Patricia Rozo ${ }^{1}$

\footnotetext{
${ }^{1}$ Universidad Nacional de Colômbia. Edifício Uriel Gutiérrez, Tranversal 38, 40-01, Ciudad Universitaria, Bogotá DC, Colombia. saulfranco@hotmail.com
}

\begin{abstract}
This article is an approach to the consequences of the internal armed conflict that Colombia has lived during the last four decades. It starts with the identification of the conflict's context and its current characteristics. It then focuses on the different manifestations and consequences of the conflict and on their deep impact on the life, quality of life, health, disease, and health services of the population. In special we refer to the high homicide rates, forced internal displacement, kidnapping and the use of antipersonnel mines. Among the most affected groups are young men, women, children, and ethnic minorities such as indigenous and afro-american people. This analysis also refers to the frequent violations of International Human Rights and to the negative impact of violence on the provision of health services. Final$l y$, general conclusions are drawn, and alternatives for studies on the problem and for possible solutions from the standpoint of the health sector are proposed.
\end{abstract}

Key words Violence in Colombia, External causes, Internal armed conflict, Health services
Resumo O presente trabalho trata das conseqüências do conflito armado interno (CAI) que a Colômbia tem vivido durante as últimas quatro décadas. Começa identificando o contexto e o momento atual do conflito. A seguir, são descritas algumas das formas, expressões e conseqüências do conflito armado interno, com maior impacto sobre a vida, a qualidade de vida, a saúde e as doenças da população e sobre os serviços de saúde no país. Especial ênfase é dada às altas taxas de mortalidade por homicídio, ao fenômeno do deslocamento forçado pela violência, aos seqüestros e às minas antipessoais. Entre os grupos populacionais mais afetados, destacam-se homens jovens, mulheres, crianças e as minorias étnicas indígenas e afrodescendentes. Esta análise também se refere ao sério problema das contínuas infrações da Lei Internacional Humanitária e aos ataques contra a Missão Médica, assim como às conseqüências negativas do conflito sobre a prestação de serviços de saúde. Para concluir, são feitos alguns comentários gerais sobre a situação descrita e dadas algumas sugestões para o estudo do problema e possíveis ações partindo do setor saúde.

Palavras-chave Violência na Colômbia, Conflito armado interno, Causas externas, Serviços de saúde 


\section{Introdução}

Faz quatro décadas que a Colômbia vive um intenso conflito armado interno(CAI), produzido pela confrontação entre o Estado e diferentes organizações armadas consideradas ilegais. O CAI colombiano tem suas raízes em um ciclo de violência anterior, nas décadas de 1940 e 1950 do século passado, entre os partidos políticos tradicionais. Porém, em sua fase atual, surgiu da conformação de organizações guerrilheiras a partir da década de 1960 do século passado, agravada pela irrupção e expansão do problema do narcotráfico, no início dos anos 70, e das organizações paramilitares, desde o começo dos anos 80.

Durante este período, o CAI foi se intensificando, degradando-se e atingindo maior complexidade, devido à diversidade de agentes, à convergência de processos que o têm estimulado e às implicações de diversos setores da sociedade civil. Ao mesmo tempo, os índices de diferentes formas de violência - tais como homicídios, desaparições, deslocamentos forçados e seqüestros - têm alcançado níveis nunca antes registrados no país. A qualidade de vida dos colombianos e colombianas tem sido seriamente afetada pelo conflito, e o próprio setor saúde tem recebido o impacto negativo das conseqüências da violência e, em ocasiões cada vez mais freqüentes, tem se convertido em vítima direta dos diferentes agentes do conflito.

Diversos estudos chamam a atenção para o volume do fenômeno da violência colombiana, em particular do conflito armado interno, e para seu impacto sobre a vida e a saúde dos colombianos e sobre o setor saúde nas diferentes regiões do país. A partir de uma síntese sobre o momento e o contexto do CAI colombiano, este documento propõe-se a apresentar um breve panorama acerca das graves conseqüências que tal conflito está tendo sobre a vida, a mortalidade e a morbidez e sobre os serviços de saúde. O documento termina com algumas considerações de análise e propostas para os setores da comunidade acadêmica internacional e da saúde interessados na análise das relações entre conflito armado e saúde e na eventual solução do conflito colombiano.

\section{Atualidade do conflito armado interno colombiano}

Convém, em primeiro lugar, definir que, no caso colombiano, trata-se de um conflito armado interno e não propriamente de uma guerra civil ou de uma série desarticulada de ações terroristas. Aceitam-se, em geral, três características para tipificar o conflito armado interno: primeiro, que as partes enfrentadas tenham um estatuto jurídico claramente desigual; segundo, que as ações dos grupos armados respondam às determinações de um comando responsável, o que não significa forçosamente a implantação de um sistema de organização militar hierárquico, semelhante ao das forças armadas; e, terceiro, que as atividades criminosas estejam dirigidas sistematicamente a um propósito político ou ideológico definido, exercendo o controle de uma parte do território ${ }^{1}$, aspecto que diferencia o CAI do aumento abrupto de atos de violência isolados.

Ao analisar estas características, fica claro que o fenômeno da violência enfrentado na Colômbia deve ser rotulado de conflito armado interno. De um lado, existem grupos armados reconhecidos, como as guerrilheiras Forças Armadas Revolucionarias da Colômbia (Farc) e o Exército de Liberação Nacional (ELN). Tais grupos vêm realizando atos violentos prolongados de diversas índoles e têm comandos organizados e reconhecidos entre seus integrantes, controlando certas áreas e regiões do país. A mesma coisa aconteceu com a aparição e o fortalecimento posteriores de grupos armados paraestatais, reconhecidos como paramilitares, como as Autodefesas Unidas de Colômbia (AUC). Estas últimas surgiram em parte como resposta à ação das guerrilhas e como organizações a serviço de empresários agrícolas, pecuaristas, agroindustriais e narcotraficantes.

Ao tentar reconhecer a origem e os processos dinamizadores do CAI da Colômbia, pode-se mencionar, de maneira sintética, os seguintes: a falta de legitimidade e a progressiva corrupção do Estado; a ausência de espaços democráticos para resolver pacificamente as controvérsias; a acumulação de crises e conflitos não resolvidos; a desigualdade crônica e crescente nos campos econômico, político e social; a desigualdade e a exclusão de amplos setores da população; a precariedade e a ineficiência da justiça, com a conseqüente sensação de impunidade; a intolerância às diferenças culturais, políticas e valorativas; e o auge do narcotráfico e do tráfico de armas como bases de sua manutenção e expansão ${ }^{2}$.

O CAI passou de basicamente focal e rural a manifestar-se em todas as regiões, com diversos efeitos sobre os setores do país. Embora em alguns governos se tenham tentado negociações políticas com alguns dos agentes armados ilegais, a resposta predominante por parte do Estado tem sido de tipo repressivo-militar. De fato, na Colômbia, 
apresentam-se por parte dos diferentes agentes do conflito perto de 2.800 ações de combate ao ano, o que representa a morte de mais de três mil combatentes $^{3}$. Hoje, é intensa a confrontação militar com as organizações guerrilheiras, enquanto se tem empreendido um polêmico processo de negociação com os grupos paramilitares, e o problema no seu conjunto torna-se mais agudo devido, fundamentalmente, a quatro aspectos: a persistência e o agravamento dos fatores determinantes do conflito; o escalamento e a degradação do conflito, que já não distingue combatentes e população civil e tem desencadeado uma verdadeira crise humanitária; o risco, potencial ou real, de que o problema comprometa a estabilidade da região; e, por último, a importância que a Colômbia tem num dos temas da agenda norte-americana atual, relacionado a produção, tráfico e consumo de narcóticos, devido ao fato de o país produzir em nível mundial dois terços da cocaína e participar ativamente do tráfico de estupefacientes ${ }^{4}$.

De acordo com o Direito Internacional $\mathrm{Hu}-$ manitário (DIH), ter o CAI reconhecido por parte de um governo não tem efeito nenhum sobre o estatuto jurídico das partes em conflito, nem limita a possibilidade de solucioná-lo por qualquer um dos meios estabelecidos e de julgar e condenar os adversários; pelo contrário, favorece a aplicação dos tratados internacionais para sua regulação ${ }^{1}$.

\section{Efeitos do conflito armado sobre a vida e a saúde da população colombiana}

São diversas, graves e complexas as conseqüências que tem o conflito armado colombiano sobre a vida, a qualidade de vida, a saúde, a atenção da saúde e a prevenção das doenças no país. Ao pretender descrevê-las, é inevitável o entrecruzamento entre formas específicas de violência e suas principais vítimas. Ao mesmo tempo, observa-se que vários fenômenos podem ser igualmente expressão e conseqüência do conflito e, portanto, afetar diversas vítimas e alterar tanto sua qualidade de vida como as distintas dimensões físicas, afetivas e psicossociais da saúde.

Tendo esclarecido estas dificuldades, são apresentados os aspectos mais relevantes do tema em questão e descritos, em primeiro lugar, quatro formas e conseqüências graves da violência atual sobre a vida e a saúde: os homicídios, o deslocamento forçado, os seqüestros e as minas contra pessoas, assinalando-se para cada fenômeno sua extensão, principais modalidades e implicações e fazendo especial referência aos meninos, meninas e mulheres vítimas do conflito. A seguir, são descritas duas das principais conseqüências do conflito sobre os serviços de saúde: as alterações em seu fornecimento e as violações da Missão Médica.

\section{Colômbia: um país homicida?}

Levando-se em conta que entre 1975 e 2004 houve no país 554.008 homicídios, com uma média de um homicídio a cada meia hora neste período, o que representa entre 10 e $15 \%$ da mortalidade total ${ }^{5}$, a resposta para a interrogação formulada resulta vergonhosamente verdadeira. Embora a configuração da curva dos homicídios na Colômbia nos últimos 30 anos (Gráfico 1) seja a resultante de diferentes processos e formas de violência, existe uma clara relação entre ela e o desenvolvimento do conflito armado interno. $\mathrm{O}$ aumento desenfreado das taxas de homicídio para cada cem mil habitantes (hpcmh) é verificado desde meados dos anos 70, atingindo o pico máximo em 1991 com $81 \mathrm{hpcmh}$. A partir de então, têm-se apresentado ondas na curva, com declínio marcante a partir do ano de 2003. A explicação deste declínio não é ainda clara, mas existem várias hipóteses. Uma delas o relaciona com a política de segurança democrática implementada pelo atual governo, baseada na contenção militar da guerrilha, com um aumento significativo de orçamento, poder e força militar. Como parte desta política, está se produzindo a desmobilização de alguns dos grupos paramilitares, cuja participação na violência homicida tem sido muito alta. Outra hipótese afirma que o declínio da mortalidade violenta deve-se também à adoção de políticas e programas de segurança e convivência cidadãs em nível local, como ocorre nas cidades de Bogotá e Medellín. Em contraste com esta situação encontrada em algumas das grandes cidades, a violência homicida intensifica-se em muitos dos pequenos municípios do país, cujas estatísticas não têm um grande impacto nos dados nacionais ${ }^{6}$.

Separando as taxas de homicídio por idade e sexo, percebe-se ${ }^{7}$ que as principais vítimas foram homens jovens, cada vez mais jovens, chegando inclusive a comprometer crianças menores de cinco anos. No departamento de Antioquia, cuja capital é a cidade de Medellín, os homicídios foram a causa da morte, em 1994, de mais da metade (53\%) das crianças de 10 a 14 anos e de $87 \%$ dos adolescentes entre 15 e 19 anos. Apesar de as mulheres terem sido vítimas dos homicídios com relativa menor freqüência do que os homens, a relação se reduziu, em menos de uma década, de 18 homens por uma mulher para 13 homens por uma mulher, 
Gráfico 1

Taxas de homicídios na Colômbia 1975-2005.

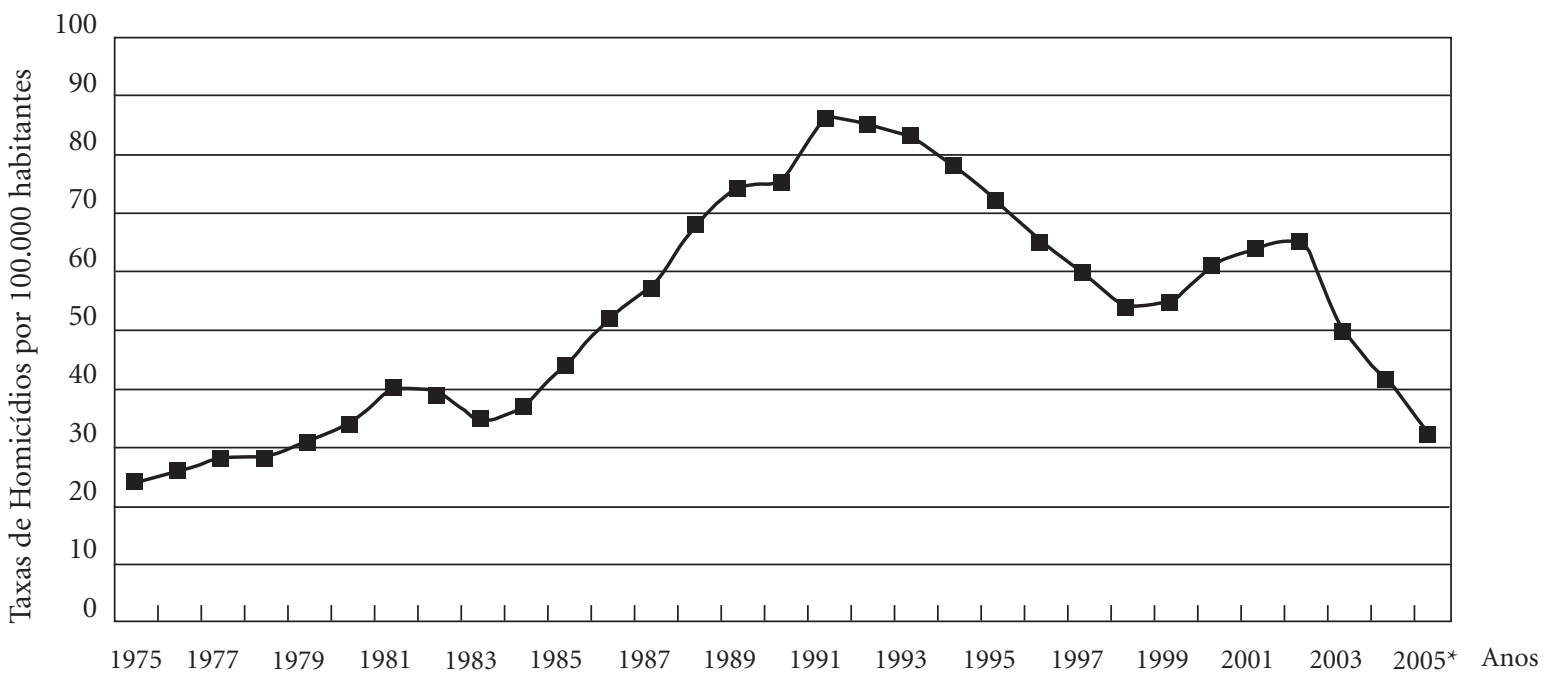

Fonte: Dados do Instituto Nacional de Medicina Legal e Ciências Forenses, Policia Nacional e CINEP.

o que indica um progressivo incremento dos homicídios das mulheres.

Em relação às diferentes regiões do país, as taxas de homicídio variam de maneira significativa de um ano para outro, expressando em boa medida a dinâmica do conflito e a maior ou menor capacidade de resposta da sociedade e do Estado no próprio nível regional. Recentemente, enquanto departamentos como Antioquia deixam de ocupar os primeiros lugares, departamentos do oriente e do sul do país, que antes tinham taxas baixas de homicídio, começam a ocupar os primeiros lugares: Guaviare, em 2001, Arauca, em 2002, Casamare, em 2004. O aumento das plantações ilícitas e o decorrente tráfico de substâncias estupefacientes, a débil presença estatal, a exploração petroleira e a luta pelo controle territorial por parte dos diferentes agentes armados explicam em boa medida esta tendência e dinâmica da violência homicida.

Por outro lado, é freqüente a prática dos "massacres", entendidos como homicídios coletivos mais de quatro mortes num mesmo episódio cometidos de maneira programada e intencional, em condições que não dão defesa às vítimas e direcionados à imobilização pelo medo, como também com o fim de estabelecer controles políticos e territoriais, o que se considera uma extrema violação do direito internacional humanitário. Segundo o PNUD, entre 1997 e 2002 houve no país um total de 930 massacres, o que dá uma média de um massacre a cada dois dias, com o resultado total de 2.630 vítimas fatais8.

Tentando delimitar o número de mortes devidas diretamente ao CAI, o PNUD estimou, em $2003^{8}$, que cada ano morrem por efeito direto da guerra entre quatro e oito mil colombianos. Se considerarmos a cifra média de seis mil vítimas fatais anuais por causa do CAI, concluiremos que, nos últimos 25 anos, a Colômbia teria perdido 150 mil vidas diretamente atribuídas ao conflito, sem contar a contribuição do mesmo, por diferentes mecanismos e interações, para outra alta cifra de homicídios de colombianos.

Outra forma de estimar o peso da violência e do conflito armado sobre a vida dos colombianos é observar o comportamento da expectativa de vida, em especial quando se compara este indicador entre homens e mulheres no país. A expectativa de vida ao nascer da população colombiana em seu conjunto tem aumentado, mas o ritmo tem diminuído, e o diferencial entre homens e mulheres tem aumentado, em boa parte devido à violência homicida. Segundo a Organização Pan-americana da Saúde (Opas) ${ }^{9}$, em 2004, a expectativa de vida ao nascer era de 75 anos para as mulheres e de 69, para os homens; isto é, seis anos de diferença a favor das mulheres e contra os homens. Por outro lado, o PNUD, no informe já citado, estima que, só durante a década de 1990, os colombianos perderam entre 1 e 1 ano e meio de expectativa de vida por causa da violência. 


\section{A tragédia do deslocamento forçado pela violência}

Segundo dados da Conferência Episcopal Colombiana e da ONG Consultoria para os Direitos Humanos e o Deslocamento (Codhes), entre 1985 e 2005, mais de 3 milhões e 600 mil colombianos foram vítimas do deslocamento forçado por causa da violência ${ }^{10}$, como se pode ver no gráfico 2. Segundo a mesma fonte, $30 \%$ desse total, isto é, um milhão e cem mil pessoas, têm sido deslocadas durante os últimos três anos e meio Aproximadamente a metade da população deslocada por violência tem menos de 18 anos $^{11}$. De acordo com um estudo da Pastoral Social ${ }^{12}$, 46,5\% dessa população são menores de 15 anos, percentual semelhante aos $48,5 \%$ obtidos para a mesma faixa na pesquisa da Opas e da Universidade de Antioquia em 200313. A Unicef e a Codhes ${ }^{14}$ estimam que, entre 1985 e 2002, cerca de um milhão e 750 mil meninos e meninas tiveram que fugir de seus locais de origem no país. Só no ano de 2005, foram deslocadas, no total, 310 mil pessoas no país, comprometendo 750 municípios como agentes de expulsão e 950, como receptadores da população expulsa. De acordo com informação oficial fornecida pela Rede de Solidariedade Social ${ }^{15}$, entidade governamental encarregada de atender ao problema do deslocamento, 90\% dos expulsos são de origem rural ou semi-rural e um terço tem ou tinha terras no seu local de origem; $50 \%$ vêm se instalar nos cinturões de miséria das grandes cidades; 9,2\% correspondem a comunidades afro-colombianas; e $3,4 \%$, a comunidades indígenas.

As conseqüências do deslocamento são diferentes em função de gênero, idade, grupo étnico, nível econômico e organizativo prévio, tipo de deslocamento, lugar de destino e condição de inserção nos novos cenários. Aos meninos (as), o deslocamento causa desnutrição, doenças de pele e infecto-contagiosas, por aumentar a vulnerabilidade deles e deteriorar as condições do ambiente onde vivem. De cada cem menores deslocados entre 1 e 4 anos de idade, somente dois têm o esquema de vacinação completo. E de cada cem mulheres adolescentes em situação de deslocamento, 35 já são mães, o dobro da média nacional, segundo o estudo da Opas já citado. Aos dados anteriores somam-se a discriminação, as maiores dificuldades de acesso aos serviços de saúde, a decomposição do núcleo familiar, o abuso físico e sexual e a exploração laboral, com as conseqüências sobre a saúde mental.

Além disso, a população adulta - com mais de 19 anos - constitui 50\% do total de pessoas deslocadas, sendo maior a porcentagem de mulheres do que de homens. Nas mulheres, a proporção de analfabetas aumenta com a idade e apresenta variações por regiões e grupos étnicos, que diminuem as possibilidades de trabalho. A média de filhos por

\section{Gráfico 2}

Deslocamento forçado na Colômbia 1985-2005.

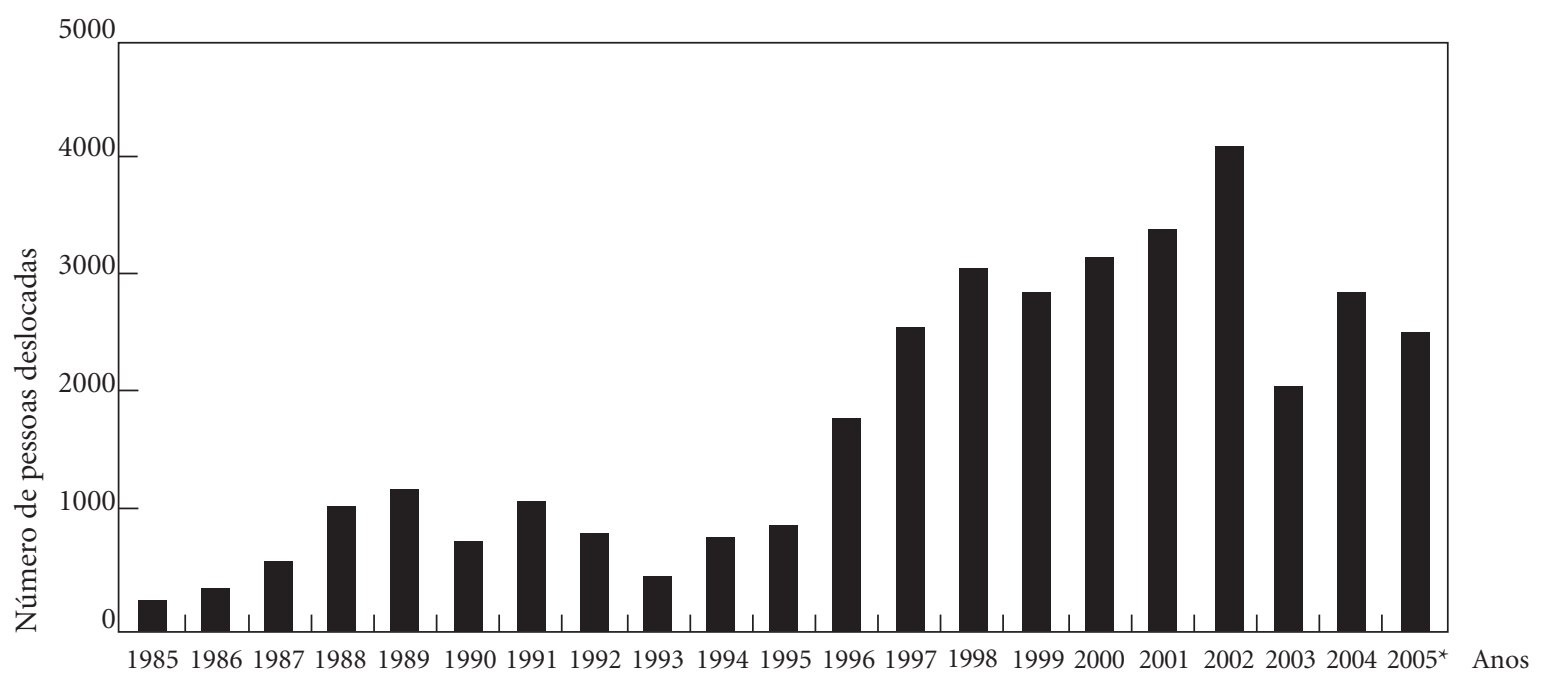

Fonte: SIDHES, Codhes.

* Até outubro 2005. 
mulher deslocada é de três, e a maioria delas, na prática, deve assumir a chefia do $\operatorname{lar}^{16} \mathrm{e}$ a responsabilidade econômica do núcleo familiar ${ }^{17}$, pela perda de seus esposos ou companheiros no meio do conflito e por eles abandonarem as responsabilidades familiares nas novas circunstâncias. Nos estudos sobre gênero do Escritório do Alto Comissionado das Nações Unidas para os Refugiados (ACNUR), que na Colômbia se dedica ao problema do deslocamento, os efeitos do deslocamento forçado significam rupturas e perdas mais fortes para as mulheres do que para os homens. No entanto, no contexto urbano, o desemprego costuma afetar mais os homens do que as mulheres ${ }^{8}$.

Entre 3 e 6\% da população em situação de deslocamento são maiores de 60 anos. Nesta faixa de idade, as mulheres constituem $70 \%$ da população deslocada ${ }^{12}$, visto que os idosos resistem a abandonar suas terras e seu ambiente. Como na dinâmica do CAI os homens e jovens são a população, mais recrutada pelos grupos armados ou as principais vítimas de assassinatos, em muitas ocasiões são os avós que ficam a cargo dos lares e permanecem no seu interior, em péssimas condições econômicas, higiênicas e sanitárias, sendo quase invisíveis socialmente.

Merece ser destacado o impacto negativo do CAI e, em particular, do deslocamento e do confinamento sobre a população indígena. Estima-se que $57 \%$ dos povos indígenas do país estão sendo afetados diretamente pelo CAI ${ }^{18}$. O confinamento imposto pelos agentes armados é uma das mais graves conseqüências do conflito para esta população $\mathrm{e}$, atualmente, um em cada três indígenas é submetido a isto. Tanto o deslocamento como o confinamento das populações indígenas apresentam-se com mais intensidade nas regiões com maior componente indígena, tais como os departamentos de Cauca, Caquetá, Chocó, Valle del Cauca, La Guajira e Vaupés ${ }^{19}$. Os povos indígenas mais afetados têm sido nesta ordem: Emera, Nasa, Embera Chami, Wiwa, Embera Katio, Kankuamo, Pijao, Guahivo, Wayú e Awa. Soma-se à gravidade das conseqüências do deslocamento o fato de que, ao serem deslocadas de suas terras ancestrais, as populações indígenas sentem carência de sentido para a vida, enfrentam uma maior aculturação e vêem aumentar o risco de extinção.

Quanto ao acesso aos serviços de saúde, estima-se que dois em cada 10 deslocados não contem com nenhum documento de acesso a eles, além de enfrentarem limitações para o reconhecimento da condição de deslocado, elevado gasto em dinheiro em consultas e medicamentos e alguma discriminação institucional, que fez com que a 30\% deles tenha sido negada atenção médica ${ }^{13}$.

\section{O horror do seqüestro}

O seqüestro, entendido como a privação forçada da liberdade, constitui uma das mais graves violações ao conjunto dos direitos humanos e, portanto, um crime de lesa-humanidade. Por suas características e pela incerteza de seu desfecho, é, além disso, um fator de deterioração da qualidade de vida tanto da vítima como das pessoas de seu círculo familiar, profissional e político, com severas conseqüências sobre a saúde, especialmente a mental.

Existem vários tipos de seqüestro, sendo mais importante para o tema deste material o seqüestro extorsivo, que combina com freqüência os elementos econômicos e políticos. De fato, no CAI colombiano, o seqüestro tem se convertido em um mecanismo freqüentemente utilizado para financiar as organizações armadas à margem da lei e para tentar alcançar objetivos políticos, tais como o envio de mensagens por intermédio de personagens altamente representativos ou a pressão para obter determinados fins, como troca de prisioneiros e demonstração de força.

As cifras disponíveis mostram um crescimento alarmante do seqüestro no mesmo período em que se desenvolveu o CAI, evidenciando sua progressiva degradação. Na década de 1970, eram seqüestradas anualmente 55 pessoas, em média. Nos anos 80, a média anual elevou-se para 296 casos, com um pico máximo de 781 casos, registrado em 1989. Na década de 1990, a média anual de seqüestros no país elevou-se para a alarmante cifra de 1.508 casos. No ano 2000 registra-se o pico mais alto de todo o período mostrado no gráfico 3, com um total de 3.706 seqüestros e uma média diária de dez seqüestros. Nesse momento, alcançou seu auge uma terrível modalidade de seqüestro coletivo, que em seguida selecionava suas vítimas definitivas, conhecida como "pesca milagrosa". A partir do ano 2000 tem havido, aparentemente, um declínio significativo do fenômeno, embora persistam sérias dúvidas sobre a confiabilidade dos registros. Segundo estatísticas do Observatório para os Direitos Humanos da Vice-presidência da República, muito inferiores às do gráfico 3 para 2004, $73 \%$ das vítimas de seqüestro registrados (908) eram do sexo masculino, enquanto os $27 \%$ restantes (342) eram mulheres. Dos 1.250 seqüestros registrados em tal ano pelo Observatório, 222 foram de menores de idade $-18 \%$ do total.

Pior do que o seqüestro são as desaparições forçadas. Segundo a Convenção Interamericana sobre Desaparição Forçada de Pessoas (1993), entende-se desaparição forçada como a privação da 
Gráfico 3

Seqüestros na Colômbia 1996-2005.

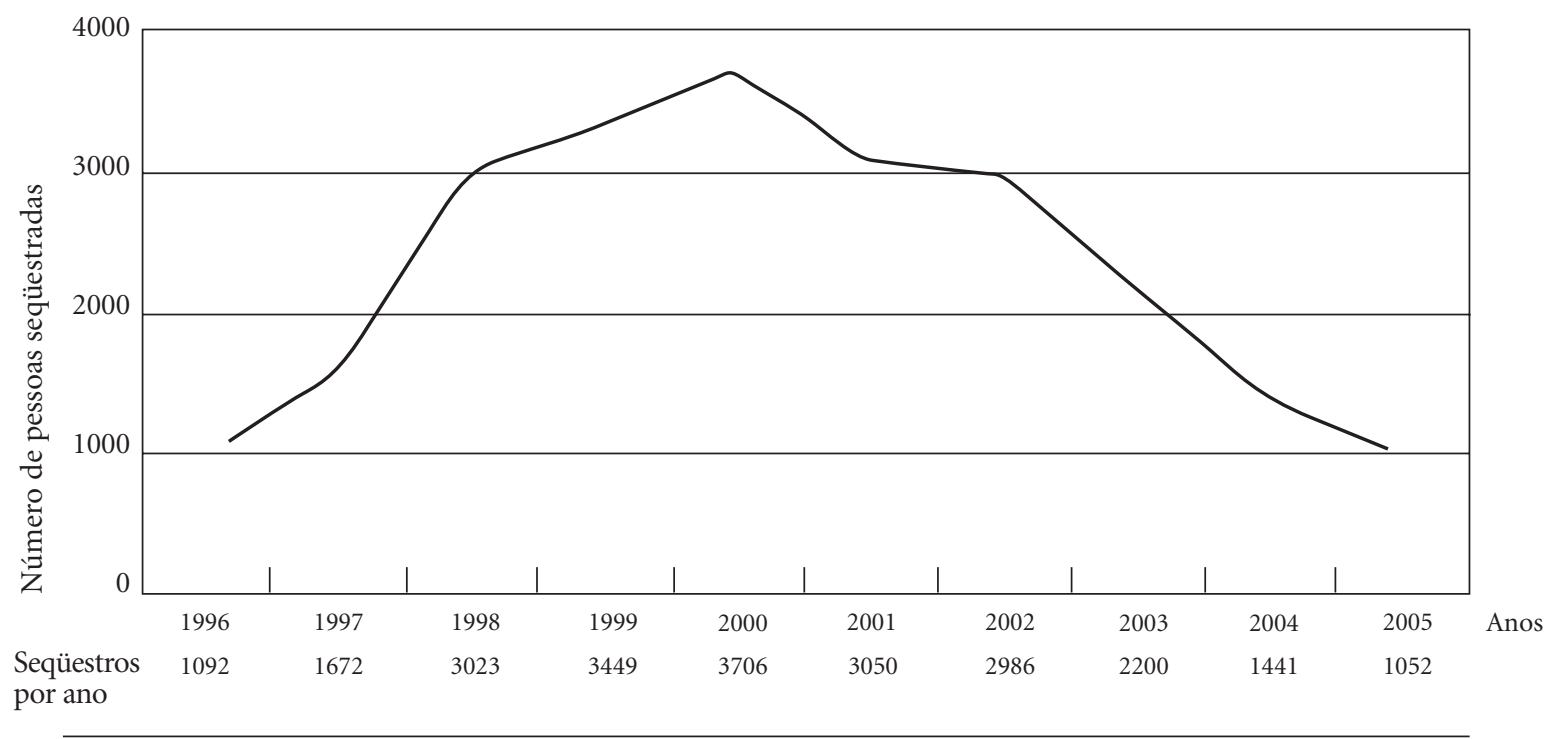

Fonte: Departamento Nacional de Planejamento. Dados sobre Violência.

liberdade de uma pessoa, qualquer que seja a sua forma, cometida por agentes do Estado ou por pessoas ou grupos de pessoas que agem com a autorização, o apoio ou a aquiescência do Estado, seguida da falta de informação ou da negativa a reconhecer tal privação de liberdade ou de informar sobre o paradeiro da pessoa, com a qual fica impedido o exercício dos recursos legais e das garantias processuais pertinentes ${ }^{20}$.

Há grande diversidade e inconsistência nos dados sobre desaparições, em função dos critérios para definir o fenômeno e das instituições que registram a informação. Segundo o Centro de Investigación Y Educación Popular (Cinep), referência anterior, no primeiro semestre de 2005 registraram-se no país 35 casos de desaparição forçada por perseguição política, $86 \%$ deles atribuídos a grupos paramilitares. No mesmo período, registraram-se 25 casos de desaparição forçada por autores não determinados, como produto da violência político-social. Por outro lado, o Comitê Internacional da Cruz Vermelha ${ }^{21}$ informa que em 2004 documentaram-se no país 279 casos de desaparição forçada relacionados com o conflito armado, que, segundo a mesma fonte, devem ser somados aos mais de dois mil casos registrados a partir de 1994. Apesar da gravidade das desaparições e de suas conseqüências para a qualidade de vida e saúde das vítimas e do seu círculo familiar e político, chama a atenção o pouco impacto que têm nos meios de comunicação e nos debates sobre o conflito.

\section{Os graves danos das minas contra pessoas}

Outro indicador da crescente degradação do conflito armado colombiano é o uso em elevação das minas contra pessoas. A dificuldade para detectá-las, distingui-las e evitá-las, e sua capacidade letal ou de produzir graves danos físicos - mutilações, amputações, perda de órgãos vitais - e complexas seqüelas psicológicas nas vítimas e em seu ambiente afetivo fazem das minas contra pessoas armas altamente nocivas, que violam o Direito Internacional Humanitário. E, visto que uma mina não desativada pode ser letal até 50 anos depois de colocada, o aumento de sua "semeadura" por parte dos grupos armados pode prolongar ainda mais o conflito e suas nefastas conseqüências. Também seu registro é impreciso e freqüentemente tendencioso. De acordo com dados do Exército Nacional, entre 1990 e junho de 2002 a Colômbia registrou mais de 1.800 explosões geradas por artefatos explosivos colocados por grupos armados ilegais ${ }^{22}$. Segundo a mesma fonte, em 411 municípios localizados em 30 dos 32 departamentos do país tem sido detectada a presença de tais artefatos. Um recente informe jornalístico ${ }^{23}$ menciona que tem havido um alarmante aumento na semeadura de minas antipessoais; já são encontradas em 627 municípios do país, o que equivale a mais de $50 \%$ do total de municípios, e produziram 2.358 vítimas em cinco anos. Por sua parte, a vice-presidência da República informa ter havido um total de 
3.409 explosões desse tipo no período de 1990 a setembro de 2003. Fatos semelhantes no ano 2000 produziram 116 vítimas; em 2001, 147 vítimas, e em 2002, 384 vítimas ${ }^{24}$. Segundo uma recente publicação ${ }^{25}$, entre janeiro e setembro de 2004 , registraram-se no país 421 novas vítimas de minas, das quais 109 morreram e 321 ficaram feridas. Do total de tal período, 127 eram civis, e deste grupo faziam parte sete mulheres e 31 crianças. Estima-se que, em geral, 14\% das vítimas são crianças.

Apesar dos esforços de diferentes instituições e organizações nacionais e internacionais para combater o uso de bombas no país, o problema e suas conseqüências continuam em elevação, como indicam os números expostos. Como agravante para a questão, enquanto quase todos os países apóiam e promovem a eliminação desses explosivos, alguns dos principais produtores de minas antipessoais, entre eles os Estados Unidos, negam-se a assinar um acordo para proibir a sua produção.

\section{Meninos, meninas e mulheres no conflito armado}

Desde o inicio do atual CAI, tem sido registrada, com preocupação, a presença de meninos e meninas nos grupos armados legais e ilegais. A partir dos anos 90, o problema tornou-se agudo e mais visível ao aumentar a consciência nacional e internacional sobre o tema. Segundo estimativas do secretário geral das Nações Unidas, da Defensoria do Povo de Colômbia, da Unicef e do Human Rights Watch, o número de menores de idade que participam dos grupos armados ilegais no país é calculado entre 11 mil e 14 mil, tornando a Colômbia o quarto país em número de meninos e meninas armados no mundo. Do total estimado, calcula-se que cerca de seis mil meninos (as), em sua maioria pertencentes à faixa de idade de 13 a 17 anos, fazem parte das organizações guerrilheiras, e que 15\% dos integrantes dos grupos paramilitares são menores de 18 anos. Somente em 1999 o recrutamento de menores de 18 anos para o exército nacional foi regulamentado. A maioria dos meninos e jovens, de 13 a 17 anos, recrutados pelos agentes armados é de origem camponesa, tem baixo nível educativo geralmente atuaram prematuramente no trabalho agro-pecuário - e advém de famílias numerosas em geral com mães, avós ou parentes como chefes de família - com freqüentes antecedentes de violência familiar. Já nos cenários do conflito, além de serem privados da infância, esses jovens convertem-se, ao mesmo tempo, em agentes e vítimas da violência, enfrentam um ambiente de guerrilheiros adultos em circunstâncias muito difíceis e enfrentam ameaças permanentes a suas vidas, segurança e integridade, sofrendo, com freqüência, violência física, sexual e psicológica. Tais circunstâncias lhes deixam marcas difíceis de apagar e superar na vida adulta, caso sobrevivam ao conflito.

O Instituto Colombiano de Bem-estar Familiar (ICF), em cooperação com outros organismos governamentais, não-governamentais e internacionais, tem realizado ações encaminhadas a promover a prevenção da vinculação de meninos, meninas e adolescentes a grupos armados ilegais que recrutam jovens ${ }^{26}$.

Ainda que haja algumas mulheres que livremente optaram por fazer parte das organizações armadas, tanto estatais como da insurgência, e dos grupos paramilitares, muitas outras foram e continuam sendo vítimas do conflito armado. Segundo documento das Nações Unidas ${ }^{27}$, a situação dos direitos das mulheres e das meninas que se encontram nas fileiras dos grupos armados ilegais continua sendo uma preocupação para o Escritório. Há mulheres e meninas combatentes que foram objeto de abusos sexuais por parte dos superiores hierárquicos. Não existe um programa especial de re-inserção para as mulheres ex-combatentes.

\section{Impacto do conflito armado sobre o setor saúde}

São múltiplas as conseqüências do conflito armado sobre o setor saúde, incluindo nele tanto as instituições, pessoas e recursos dedicados a prestar serviços de saúde, como os dedicados à formação de pessoal profissional e técnico, à pesquisa em saúde e à formulação e implementação de políticas sanitárias. O CAI coloca urgentes demandas para os serviços assistenciais em relação à atenção oportuna e adequada às vítimas. Porém, igualmente consome grande parte dos recursos de muitas das instituições assistenciais, como também coloca sérias questões para os esquemas e modelos de formação de pessoal em saúde, para as políticas sanitárias do país e para as prioridades de pesquisa em saúde.

\section{As freqüentes infrações contra a Missão Médica}

Entendida como o conjunto de pessoas, instalações, materiais, equipamentos e atividades encaminhados à prestação dos serviços de saúde em situações ou zonas de conflitos armados, a Mis- 
são Médica (MM) está protegida pelo Direito Internacional Humanitário (DIH) nos quatro Convênios de Genebra, no Protocolo II adicional aos Convênios de Genebra e no artigo 3 comum de ditos convênios. No caso colombiano conta-se ainda com a regulamentação do emblema protetor que permite a identificação de pessoas e instituições ${ }^{28}$.

Diferentes pesquisas dão conta da gravidade e freqüência dos fatos que atentam contra a MM na Colômbia. Segundo estudo realizado pelo Comitê Internacional da Cruz Vermelha ${ }^{29}$, entre 1995 e 1998 foram cometidas 468 infrações. A maioria contra a vida e a integridade pessoal, seguida por atentados à infra-estrutura sanitária. Estas ações deixaram 341 vítimas, das quais 76 eram pessoas ligadas ao setor, que foram assassinadas. Estudo recente do Ministério da Proteção e a Opas ${ }^{30}$ registrou um aumento progressivo nas infrações, no período de 1999 a 2002, passando de 29 casos registrados em 1999 para 236 casos, em 2002. Segundo o Instituto de Estudos para o Desenvolvimento e a Paz (Indepaz), entre 1999 e 2002, 279 funcionários do setor foram ameaçados. Até agosto de 2004, tinham-se registrado 662 infrações com 604 vítimas, sendo as vítimas das infrações contra a vida e a integridade pessoal 98\% delas. Entre 2003 e 2005, o Ministério de Proteção Social registrou um total de 196 infrações contra a MM, média de uma infração a cada seis dias durante o período ${ }^{31}$.

Outra fonte de informação a respeito, a Associação Nacional de Trabalhadores de Hospitais e Clínicas (Anthoc), registrou, entre janeiro de 2001 e setembro de 2003, 633 infrações, quase todas relacionadas com a vida e a integridade do pessoal de saúde: 49\% de ameaças, 29\% de deslocamentos do pessoal e 84 casos (13\%) de homicídios que afetaram em particular auxiliares de enfermagem, médicos, condutores e promotoras de saúde. Este número de vítimas fatais dá uma média de um homicídio de pessoal sanitário a cada 12 dias, durante os 33 meses do registro ${ }^{37}$.

No grupo de infrações à infra-estrutura, as ambulâncias têm sido, com freqüência, alvo de ataques diretos ou de roubos para cometer ações criminosas, fazendo delas objetivo militar. Um caso dramático é o da ambulância do município de San Carlos (Antioquia), que sofreu três atentados em quatro anos; no último deles morreram quatro de seus ocupantes: uma auxiliar de enfermagem, uma mulher no último mês de gravidez e sua irmã.

Outra situação grave é a restrição por parte dos grupos armados à passagem de medicamentos para algumas comunidades, com o argumento de que são ajudas para os combatentes do bando contrário. O testemunho de um indígena é claro: Todos estes meninos estão mortos porque não tiveram droga para sobreviver. Os velhos também, porque não os deixam sair doentes para a vila. O governo tenta mandar o remédio, mas a guerra não deixa ele chegar ${ }^{32}$. A disponibilidade e distribuição de medicamentos para o tratamento da leishmaniose converte-se numa tática militar, controlada pelas forças armadas. Quem dispõe deles, mesmo que seja um paciente, pode ser catalogado como insurgente ou ao menos como suspeito.

É importante destacar também a situação de quase 40 profissionais da saúde que têm sofrido, nos últimos três anos e meio, detenções arbitrárias e processos da justiça, sob suspeita de colaboração com os agentes armados à margem da lei. $\mathrm{O}$ código de Ética Médica e o DIH estabelecem como dever dos profissionais a atenção a quem a necessitar, sem distinção alguma. As condições do conflito e a posição de sua negação por parte do atual governo põem os profissionais numa situação complicada: se derem atenção aos agentes armados ilegais, podem ser julgados pelo governo como colaboradores do terrorismo; se não o fizerem, podem se tornar alvo militar para os agentes armados nãogovernamentais ${ }^{33}$.

As infrações relativas à MM têm contribuído também para favorecer surtos epidêmicos e o ressurgimento de algumas doenças transmissíveis. Tal é o caso do surgimento da febre amarela nos primeiros meses do ano 2004, a partir da Serra Nevada de Santa Marta e do Catatumbo, onde grupos armados ilegais impediram o trabalho das unidades de saúde nas ações, tanto preventivas como curativas. Esse mesmo tipo de atividade tem contribuído nos departamentos das áreas em conflito para o ressurgimento de doenças transmitidas por vetores, como a malária, a leishmaniose e a doença de Chagas $^{34}$.

Apesar da freqüência e da gravidade das infrações contra a MM e de suas conseqüências sobre o pessoal de saúde e sobre o atendimento à população, é mínimo o apoio dado ao pessoal afetado por parte do Estado, de entidades governamentais e mesmo de organizações humanitárias. Um estudo na busca ativa de casos, realizado em 11 municípios dos departamentos de Nariño e Boyacá $^{35}$, evidencia o que foi afirmado anteriormente: $98 \%$ dos entrevistados manifestaram não ter recebido nenhum tipo de apoio, e só $2 \%$ reconheceram ter recebido algum apoio de tipo trabalhista. O mesmo trabalho destaca que 52\% do pessoal não têm conhecimento algum sobre o 
DIH, 44\% têm conhecimento escasso e somente $4 \%$, correspondentes aos diretores dos hospitais, possuíam conhecimento adequado sobre DIH.

\section{As limitações do atendimento de saúde devido ao conflito armado}

São variadas as formas por meio das quais o CAI interfere negativamente no acesso da população aos serviços de saúde e dificulta ou impossibilita que o pessoal de saúde possa cumprir suas funções, como prevenção, cura e reabilitação das enfermidades nas áreas de conflito.

Na perspectiva do pessoal de saúde, o conflito armado reduz as possibilidades de prestação oportuna e adequada do atendimento necessário e, em algumas ocasiões, chega a impossibilitá-la. Os mecanismos são muito diversos, alguns já enunciados no aparte sobre obstáculos para a Missão Médica. Como conseqüência deste tipo de situação, as condições de trabalho nas instituições de saúde se fazem mais tensas, arriscadas e menos agradáveis. Existem áreas do país para as quais a intensidade do conflito impossibilita o envio de pessoal profissional e técnico de saúde.

Outro fator determinante de deterioração da qualidade e integralidade dos serviços nas áreas de conflito tem a ver com a disponibilidade e a utilização dos recursos do setor. Concretamente: todos os agentes armados pretendem manter ampla margem de influência ou controle sobre o pessoal, as instituições e os recursos do setor saúde nas áreas de conflito. E, para isso, utilizam desde solicitações e advertências até ameaças, roubo, bloqueios, retenções e assassinatos seletivos. Na Colômbia, a privação do serviço de energia elétrica tornou-se uma estratégia dos grupos insurgentes para pressionar, intimidar e controlar a população. Para o setor saúde, mais do que para nenhum outro, esse serviço é essencial para o funcionamento de seus equipamentos básicos de iluminação, diagnóstico, tecnologia cirúrgica e ar-condicionado. Ao se reduzirem, perderem-se e encarecerem os recursos, dá-se à população com resultado líquido maior falta de proteção e crescimento do risco tanto de se aumentar a taxa de mortalidade por certas patologias como de não se ter o atendimento de urgência necessário em caso de ataques violentos e ocorrências agudas de diferente natureza. Essa situação de falta de proteção termina afetando os próprios agentes do conflito armado, pois, também eles se transformam em vítimas e requerem atenção. Daí a importância de defender a neutralidade do setor e do pessoal de saúde em serviço ativo e de garantir que todos os agentes a reconheçam e acatem.
A informação confiável e oportuna é fundamental em saúde para escolher e decidir sobre políticas e ações, para prevenir ocorrências, para formular diagnósticos e prognósticos e para dar atendimento adequado. Ainda que, em nível geral, no sistema de saúde do país, persistam sérias dificuldades quanto à qualidade e à confiabilidade da informação, nas áreas de conflito armado, a informação torna-se arma de guerra, difícil de ser reunida e, quando existente, de difícil acesso. Pode-se afirmar que a informação completa e confiável é uma das primeiras baixas em situações de guerra. E sem ela as ações apresentam mais risco e incerteza em todas as áreas, inclusive na de saúde.

\section{Conclusões e sugestões}

Conceitualmente, toda nação é soberana, e seus cidadãos têm o direito à insurgência para acabar com a opressão e construir uma sociedade e um estado mais justos. A humanidade, porém, conseguiu construir códigos mínimos que seriam válidos nas guerras entre países e no interior dos países, pautas para evitar ou prevenir excessos e normas para a proteção das vítimas e da população civil. Esse é o propósito do Direito Internacional Humanitário (DIH). Sem questionar aqui a legitimidade do conflito armado interno que vive a Colômbia, a documentação e a argumentação apresentadas permitem evidenciar que, na sua fase atual, esse conflito tem ultrapassado as normas do DIH e, na sua dinâmica, está violando quotidianamente os mínimos requisitos de humanidade. A primeira tarefa na via da superação deste conflito deve ser convencer as partes de tal fato e garantir que todos os agentes armados acatem efetivamente as normas humanitárias internacionais. Enquanto os agentes acreditarem que tudo é valido para atingir seus objetivos particulares, nenhuma solução é possível. A principal parte afetada continuará sendo a população civil, em particular seus integrantes mais expostos e vulneráveis.

A informação apresentada neste material traz também elementos para continuar sustentando que a violência é o principal problema de saúde pública que a Colômbia enfrenta hoje. As altas taxas de mortalidade homicida; a significativa deterioração da qualidade de vida, tanto das vítimas diretas do conflito armado como das vítimas diretas ou indiretas de outras formas de violência; a morbidez física e psicoemocional derivada do CAI; as limitações cada vez maiores para a prestação e recepção de serviços de saúde adequados e oportunos; os altíssimos custos humanos, 
econômicos, demográficos e sociais da violência; e os desafios que ela coloca para os processos de formação de pessoal profissional e técnico em saúde, para a pesquisa que o setor realiza, para as políticas e ações que desenvolve e para os serviços que presta ou deixa de prestar parecem ser argumentos suficientes para priorizar a violência no amplo panorama da problemática sanitária nacional. Não se trata de desconhecer ou subvalorizar outros graves problemas de saúde pública pendentes, mas sim de olhar a realidade e trabalhar pelo fundamental, como a reivindicação elementar do direito à vida.

Mais como conclusão do que como hipótese, pode-se afirmar que a vida, a saúde e o bem-estar dos colombianos e colombianas são os maiores perdedores no atual conflito colombiano. Mais de meio milhão de vidas sacrificadas em 30 dos 40 anos da confrontação armada são o primeiro, mas não o único dos argumentos. E se, no ideário original de alguns dos agentes históricos do conflito, a reivindicação da saúde e da vida digna para a maioria da população ocupou algum lugar, este projeto foi desviado no caminho e hoje é negado pelos imperativos de uma guerra desenfreada.

Para o pessoal de saúde e para a população em geral, é eticamente incorreto apostar em favor de uma guerra cuja causa - a vida e o bem-estar de todos - já está derrotada e não parece interessar a nenhum de seus protagonistas, além do discurso anestésico.

Na raiz dos problemas da Colômbia - incluindo seu conflito armado - encontra-se uma desigualdade antiga, sempre crescente e em todos os níveis da vida em sociedade. No campo da saúde e da qualidade de vida, tais desigualdades têm chegado a ser escandalosas, como evidenciam as diferenças diante da morte, na distribuição dos recursos e no acesso real aos serviços de saúde. $O$ trabalho pela eqüidade em saúde, como parte de um projeto de eqüidade global, é o sentido essencial do enunciado: o direito à saúde é uma via para a paz. Se na motivação primária do enfrentamento, hoje fora de controle, esteve a rebeldia contra a desigualdade, por um ordenamento eqüitativo, o trabalho pela eqüidade em saúde estaria na direção correta da resolução, esta sim radical, do problema. A outra cara do mesmo tema consiste em afirmar que aceitar passivamente e manter ativamente um modelo de saúde que aprofunda a desigualdade é continuar alimentando o conflito e afastando para longe qualquer possibilidade de solução.

O que pode fazer a saúde pública diante da violência? A primeira tarefa da saúde pública diante da violência deve ser reconhecê-la como um problema também seu. Não se trata de se apropriar da violência ou de buscar remédios para ela, mas de reconhecer que ela está dentro de suas preocupações e interesses e contribuir para compreendêla - em conjunto com outros campos do conhecimento -,enfrentá-la - em conjunto com outras práticas - e superá-la. Por sua própria natureza, a violência transcende os territórios da saúde pública. Porém, por suas conseqüências negativas sobre a vida e o bem-estar das pessoas e da população em geral, ela faz parte da área de interesse da saúde pública. É necessário enfatizar que o pior que pode fazer a saúde pública diante da violência - e o que vale para ela vale também para os conflitos armados - é continuar a desconhecê-la e a considerá-la objeto alheio, distante e quase impossível de ser enfrentado.

Concretamente, a saúde pública pode dar grandes contribuições para o estudo da violência, para seu registro e investigação, para a adequada atenção de suas vítimas, para a formulação conjunta de estratégias, políticas e programas para preveni-la ou enfrentá-la, para a formação de pessoal capacitado para entendê-la e disposto a participar do seu enfrentamento, para a inclusão de valores positivos. E isto, mesmo em condições ainda mais difíceis e de risco, a saúde pública pode e deve fazer diante de situação de conflito armado como a que continua vivendo a Colômbia.

\section{Colaboradores}

S Franco, CM Suarez, CB Naranjo, LC Báez and P Rozo participaram igualmente de todas as etapas da elaboração do artigo. 


\section{Referências}

1. Comité Internacional de la Cruz Roja. Comentario del Protocolo del 8 de junio de 1977 adicional a los Convenios de Ginebra del 12 de agosto de 1949 relativo a la protección de las víctimas de los conflictos armados sin carácter internacional (Protocolo II). In: Oficina en Colômbia del Alto Comisionado de las Naciones Unidas para los Derechos Humanos. Compilación de jurisprudencia y doctrina nacional e internacional. Volume III. Bogotá: Plaza y Janes Editores; 2003. p. 41.

2. Guzmán G, Fals O, Umaña E. La violencia en Colômbia. 2a ed. Bogotá: Editorial Taurus; 2005. (Tomo I).

3. Fundación Seguridad y Democracia. Disponível em http//www.seguridadydemocracia.org

4. Vargas R. Fumigación y conflicto. Políticas antidrogas y deslegitimación del Estado en Colômbia. Bogotá: Tercer Mundo editores; 1999.

5. Franco S. Panorama general de la violencia en Colômbia [tese]. Bogotá: Interfacultades en Salud Pública; 2005.

6. Programa de las Naciones Unidas para el Desarollo. Boletín Hechos del Callejón 2005; 2:2-4.

7. Franco S. El Quinto: no matar. Contextos explicativos de la violencia en Colômbia. Bogotá: Instituto de Estudos Políticos e Relações Internacionais (Iepri), Tercer Mundo Editores; 1999.

8. Programa de las Naciones Unidas para el Desarollo. Informe de Desarrollo Humano 2003. El conflicto, un callejón con salida. Bogotá: PNUD; 2003.

9. Organização Pan-americana da Saúde. Situación de salud en Colômbia. Indicadores básicos 2004. Bogotá: Opas; 2005.

10. Rojas J. Notas sobre desplazamiento. Impreso. Bogotá; 2006.

11. Ospina P. Capacitación y servicios de salud sexual y reproductiva para jóvenes desplazadas en Colômbia. RMF 2003; 15:7-14.

12. Rico A, Castillo O. Población en situación de desplazamiento en Colômbia. Bogotá: Secretariado General de la Pastoral Social, Sección Movilidad Humana; 2004.

13. Organização Pan-americana da Saúde, Universidad de Antioquia. Series de Salud y Desplazamiento. Módulo 1. Medellín: Opas 2003. (Módulo 1).

14. Consultoria para los Derechos Humanos y el Desplazamiento. Niños desplazados por la violencia: rostros inocentes de una tragedia acumulada. In: Rojas J. Un país que huye: desplazamiento y violencia. $2^{\mathrm{a}}$ ed. Bogotá: Publicaciones Codhes; 2003.

15. Red de Solidariedad Social. [acessado 2005 Dez 20]. Disponível em: http//www.red.gov.co/estadisticasparamedios/

16. Meertens D. El futuro nostálgico: Desplazamiento, terror y género. Revista Colômbiana de Antropología 2000; 36:112-34

17. Consultoria para los Derechos Humanos y el Desplazamiento. Boletín Codhes informa 482004 Abr.

18. Consultoria para los Derechos Humanos y el Desplazamiento. El desplazamiento forzado interno en Colômbia. Bogotá: Codhes; 2002.

19. Consultoria para los Derechos Humanos y el Desplazamiento. Informe especial: los indígenas en Colômbia: entre el hambre y el miedo. Bogotá: Codhes; 2004.
20. Centro de Investigación Y Educación Popular, Justicia y Paz. Banco de datos de violencia política. Noche y Niebla 2002; 26.

21. Comité Internacional de la Cruz Roja. Informe de actividades 2004. Bogotá: CICR; 2004.

22. Programa de las Naciones Unidas para el Desarollo. Boletín Hechos del Callejón 2005; 3:9-11.

23. Las minas cercan a 289 pueblos más. El Tiempo 2006 Mar 24 ; p. 1.

24. Vicepresidencia de la República. Observatorio de minas antipersona. Bogotá; 2003.

25. Campaña Colômbiana contra Minas. Monitor de minas terrestres 2004. Bogotá; 2004.

26. Programa de las Naciones Unidas para el Desarollo. Boletín Hechos del Callejón 2005; 4:12-14.

27. Organización de las Naciones Unidas. Informe del Secretario General. Documento E/CN.6/2000/PC/2

28. República de Colombia. Ministerio de Protección Social. Manual de uso del emblema protector de la Misión Médica en Colômbia. Bogotá: Ministerio de Protección Social; 2003.

29. Comité Internacional de la Cruz Roja. Infracciones a los Derechos de la Misión Médica en el Conflicto Armado Colômbiano 1995-1998. Bogotá: CICR; 1999.

30. República de Colombia. Ministerio de la Protección Social, Organización Panamericana de la Salud, Organización Mundial de la Salud. Manual de la Misión Médica. Bogotá: Ministerio de la Protección Social, Opas/OMS; 2004.

31. Ministerio de la Protección Social. Infracciones reportadas 2003-2005. Bogotá: Comunicación Personal; 2006.

32. Plataforma Colombiana de Derechos Humanos. El Embrujo continúa. Una Misión Maltratada por la Guerra. Bogotá: Comunicación Personal; 2005.

32. Médicos por la Guerra. Los rituales mágicos de los Jaibanàs. El Tiempo [periódico na Internet]. [acesso $2003 \mathrm{dez}$ ]. Disponível em: http//www.eltiempo.com

33. Presos por atender guerrilleros? Médicos, en el dilema de la Guerra. [acesso 2004 nov.]. Disponível em: http//www.eltiempo.com

34. Ataques de grupos armados contra misiones médicas pasaron de 29 en 1999 a 239 en el 2002. [acesso 2004 set.]. Disponível em: http//www.eltiempo.com

35. Báez L, Madroñero V, Franco S. El conflicto armado interno y su impacto sobre la Misión Médica en Colômbia. El caso de once municipios en Nariño y Boyacá. Revista Odontología 2003; 22(2): 23-9.

Artigo apresentado em 4/03/2006

Aprovado em 17/03/2006

Versão final apresentada em 17/03/2006 